\title{
Adapting Peer-Writing Techniques to Asian Technologies and Cultures
}

Japanese and Chinese-as well as Westernstudents write better for peers than teachers. Although talented, Japanese and Chinese students are not highly motivated to do their best in college courses because they are guaranteed jobs after graduation. To provide stimulus for greater effort, peer-writing approaches to composition courses can be effective in encouraging Asian students to write better compositions. However, the low level of technology available in language classrooms (other than audio listening laboratories) and cultural concerns-such as the need to preserve face and passiveness (reinforced in Confucian cultures)-necessitate some adaptations, primarily anonymity for the students whose writing is under discussion; in addition, more preparation of materials and explanation on the part of teachers is required.

\section{Exercises in Communication}

The peer-writing approach to composition courses works well with American students because it enables them to see their assignments as exercises in communication. When students write only for the teacher's consumption, they often have a difficult time relating such artificial use of writing to anything that exists in their "real," non-academic world.

For students of English as a Foreign Language (EFL) living in a non-English-speaking culture, composition assignments can seem even more removed from their world. The peer-writing approach in this situation, too, can lead to greatly improved writing because students become eager to communicate with one another through their compositions. In fact, Japanese and Chinese university students-who have seldom been asked their opinions on anything during the course of their education-are delighted to express their views on a wide range of topics, once they have been convinced that assertiveness is permissible.

However, differences in culture and the level of available technology make adaptation of peerwriting techniques necessary in Asian classrooms. In fact, the adaptations are so many that, at first glance, early in the semester, the approach may not resemble peer-writing at all.

In U.S. classrooms, the technology available makes the sharing of compositions with peers easily achievable. At the very least, students can come with inexpensive photocopies of their compositions and pass them around the class. At some American universities, composition classrooms are equipped with networked computers, and students can-if it is part of the pedagogical approach to the course-revise one another's compositions on the screens of the networked computers.

\section{Available Technology in Asian Cultures}

Computers are not so readily available in Japanese classrooms and will, perhaps, become even less so for English classrooms when the Ministry of Education's kanji based computer standard is realized. There are, however, overhead projectors and 24-hour convenience stores with coin-operated copy machines readily available in Japan.

In China, the scarcity of paper puts photocopying for large-sized classes out of the range of most students' financial resources as well as the 
range of most departmental budgets. A foreign language department is considered most fortunate if it has reached the level of hand-cranked mimeograph machines. What is a more likely scenario is that of the departmental clerk-or the teacher-fastening a stencil onto a silkscreen frame and inkrolling the copies one sheet at a time.

The great pedagogical concern in peer-writing courses is the sharing of the class' writing. In high-tech educational environments, this sharing can be enticingly done via computer technology. In low-tech educational environments common in Asian countries, a chalkboard covered in dustemitting, multi-hued Chinese chalk may have to serve a similar function. No matter what the level of technology available in the classroom, inventive teachers and students will always find-and must find-ways to share the class' writing. Although adapting to the technology available is necessary both on the part of teachers and students, perhaps, of even greater necessity is the adaptation of peer-writing strategies in terms of cultural concerns.

\section{Writing as Something Other Than Communication}

Students in Chinese and Japanese universities are there because they have performed well on test after test in their school careers. Education is mandatory (and in Japan, free) only until the end of junior high school. Students are very much aware of how their high school and university rank in comparison to other educational institutions in the region. Although each student is, as it were, the "cream of the crop," all students can always tell the interested listener of a dozen other schools in which students are even better.

Furthermore, Asian students are also very much aware that because they have been admitted to a university, they are guaranteed a good job for the rest of their lives (or until they marry, in the case of Japanese women). Hence, Asian students tend not to be the most motivated students in the world.

Because they know there is only one right answer to every question, students in Chinese and Japanese universities do extremely well on test after test. How do they discover the one right answer? The discovery is not all that difficult: Teachers give out the right answer, and Asian students memorize the right answers given out by the teacher. If the class happens to be a composition class, it means that there is one right way to express an idea, and the teacher knows this one right way.

By the time they reach the university, Japanese and Chinese students have been studying English for six years. The emphasis has been on grammar and vocabulary, and the classes, in all likelihood, have not been taught in English. This means that students view composition in English as a means of using various grammatical constructions at worst or as an exercise in translation from their native language at best. Generally, Asian students do not think of writing in English as a method of communication-a view reinforced by the English used in advertising in Japan and China.

\section{Nails That Stick Up Will Be Hammered}

Asian students must preserve face. On the one hand, they must not be shamed in front of others; on the other hand, they must not be singled out for praise either. As the Japanese put it, "The nail that sticks up will be hammered down."

A strategy such as passing out multiple copies of student compositions to the class for discussion-common in American composition classrooms-needs to adapted for use in Asian composition classrooms. Because of the discomfort of Asian students in being singled out in front of the class (coupled with the frequent tendency to plagiarize-partially because of strong cultural emphasis on repeating nearly verbatim what an authoritative source has said)-it is necessary to look over the students' papers first and choose those to be presented to the class anonymously.

By sharing the compositions anonymously, teachers can ruthlessly criticize and tear apart the compositions without students being embarrassed or, as is more often the case, we can praise particularly vivid phrases and clever sentence constructions without making the authors of such well-written ideas the victim of what the Chinese call "the red-eyed disease," namely, envy. 
From the 30 papers handed in by a typical class, the two or three "best" compositions can be thoroughly discussed in the 90-to 110-minute class period, with sufficient time left over for warm-up exercises and a "practice run" at the next assignment. During the course of a semester, everyone in the class will have produced something that can credibly be presented as one of the "two or three best" compositions.

Although "discussion" is a hallmark of the peer-writing composition class, for the first few months, teachers do most of the talking. After years of listening passively to teachers, Asian students are reluctant to venture suggestions or discuss topics. However, pedagogical strategies of unrelenting praise of what is good in the studied compositions, multiple suggestions for improving what is not so good, and judicious calling on students who are sure to make positive contributions eventually result in class participation.

It is advantageous, too, to assign writing that can readily be shared with the class: instructions for tying shoes or handling chopsticks which the class tries to follow as they are read aloud; new lyrics to familiar melodies with which the class can "sing along." The effectiveness or ineffectiveness of such instructions or lyrics is readily apparent to everyone trying to follow along. With anonymous writing that can be easily shared with the class, students feel more comfortable in pointing out errors or possible improvements.

\section{Politeness at All Costs}

A common practice in American composition classes-having first drafts checked by at least two classmates before a second draft is handed in-fails miserably in Asian classrooms. Requiring a class of Chinese students-who share dormitories by department and take all the same courses together-to engage in such a common practice results in classmates unwilling to say anything more specific than "good work" or "interesting idea."

Why? In the U.S., where composition classes meet more frequently than in Asia, there is much more class time available for students to work together in pairs or small groups on revision before presenting the final drafts more formally. And, more importantly, the U.S. students feel more free to comment and criticize because in their mobile society, they are not going to spend the rest of their lives in the same city with their present classmates, nor are they even going to attend the same classes all day and live in the same dormitories at night. In the U.S., associations formed in school are not necessarily going to have a major influence on the course of a student's career. Not so in Asian cultures. Asian students, especially the Chinese, can look forward to a lifetime of togetherness; politeness must be maintained at all costs.

\section{Effects of Peer-Writing Techniques on Composition}

When compositions are written for a peer audience, the topics (when selected by students) are much more interesting and the content is much less bland (as it is early in the course when students are still writing "for the teacher"). Perhaps, because of the anonymity, students even discuss a lot of unpopular political topics. Teachers of composition in China, however, try to keep classes apolitical, primarily because of the prevalence of party spies.

The best measure of the success of peer-writing in Asian classrooms is the number of students who seek out other English audiences. They get so "hooked" on expressing themselves well in English that they write letters to the editor and submit articles to English-language newspapers; some students even start English-language school magazines.

\section{Contributor Profile}

Thomas I. Bradley and Margaret Orleans are a husband and wife team with a total of 31 years' experience teaching English as a first and second language. Most recently, they taught at Fuzhou University and Liaoning University in the People's Republic of China. Currently teaching at private institutions of higher education in Hiroshima, Japan, Thomas I. Bradley and Margaret Orleans can be reached at the following address: Hiroshima University of Economics, 37-1 Gion 5-chome, Asaminami-ku, Hiroshima-city, 731-01 Japan. Phone: 082-874-3041. 